\title{
Shorter length of hospital stay for hip fracture in those with dementia and without a known diagnosis of osteoporosis in the USA
}

Rafia S. Rasu ${ }^{1,2}$, Rana Zalmai ${ }^{1}$, Aliza R. Karpes Matusevich ${ }^{1}$, Suzanne L. Hunt ${ }^{3}$, Milind A. Phadnis ${ }^{3}$ and Nahid Rianon ${ }^{4,5^{*}}$ (D)

\begin{abstract}
Background: About 50\% of all hospitalized fragility fracture cases in older Americans are hip fractures. Approximately $3 / 4$ of fracture-related costs in the USA are attributable to hip fractures, and these are mostly covered by Medicare. Hip fracture patients with dementia, including Alzheimer's disease, have worse health outcomes including longer hospital length of stay (LOS) and charges. LOS and hospital charges for dementia patients are usually higher than for those without dementia. Research describing LOS and acute care charges for hip fractures has mostly focused on these outcomes in trauma patients without a known pre-admission diagnosis of osteoporosis (OP). Lack of documented diagnosis put patients at risk of not having an appropriate treatment plan for OP. Whether having a diagnosis of OP would have an effect on hospital outcomes in dementia patients has not been explored. We aim to investigate whether having a diagnosis of OP, dementia, or both has an effect on LOS and hospital charges. In addition, we also report prevalence of common comorbidities in the study population and their effects on hospital outcomes.
\end{abstract}

Methods: We conducted a cross-sectional analysis of claims data (2012-2013) for 2175 Medicare beneficiaries ( $\geq 65$ years) in the USA.

Results: Compared to those without OP or dementia, patients with demenia only had a shorter LOS (by 5\%; $P=.04$ ). Median LOS was 6 days (interquartile range [IQR]: $5-7$ ), and the median hospital charges were $\$ 45,100$ (IQR: $31,500-65,600)$. In general, White patients had a shorter LOS (by 7\%), and those with CHF and ischemic heart disease (IHD) had longer LOS (by 7 and 4\%, respectively). Hospital charges were 6\% lower for women, and 16\% lower for White patients.

* Correspondence: Nahid.J.Rianon@uth.tmc.edu

${ }^{4}$ Department of Family and Community Medicine, The University of Texas Health Science Center at Houston, McGovern Medical School, 6341 Fannin Street, \#JJL 324C, Houston, TX 77030, USA

${ }^{5}$ Division of Geriatric and Palliative Medicine, Department of Internal Medicine, The University of Texas Health Science Center at Houston, McGovern Medical School, TX, Houston, USA

Full list of author information is available at the end of the article

C The Author(s). 2020 Open Access This article is licensed under a Creative Commons Attribution 4.0 International License, which permits use, sharing, adaptation, distribution and reproduction in any medium or format, as long as you give appropriate credit to the original author(s) and the source, provide a link to the Creative Commons licence, and indicate if changes were made. The images or other third party material in this article are included in the article's Creative Commons licence, unless indicated otherwise in a credit line to the material. If material is not included in the article's Creative Commons licence and your intended use is not permitted by statutory regulation or exceeds the permitted use, you will need to obtain permission directly from the copyright holder. To view a copy of this licence, visit http://creativecommons.org/licenses/by/4.0/ The Creative Commons Public Domain Dedication waiver (http://creativecommons.org/publicdomain/zero/1.0/) applies to the data made available in this article, unless otherwise stated in a credit line to the data. 
(Continued from previous page)

Conclusion: This is the first study evaluating LOS in dementia in the context of hip fracture which also disagrees with previous reporting about longer LOS in dementia patients. Patients with CHF and IHD remains at high risk for longer LOS regardless of their diagnosis of dementia or OP.

Keywords: Hip fracture, Dementia, Length of stay, Osteoporosis, Costs, Medicare, Older adults

\section{Background}

Hospital related outcomes, including length of stay (LOS) and hospital charges, are significant challenges faced by the health care system as the incidence of hip fracture rises beyond what is predicted every year [1]. About $50 \%$ of all hospitalized fragility fracture cases in older Americans $(\geq 65$ years old) are hip fractures [2], which are responsible for more than 300,000 hospitalizations each year [3-5]. In the USA, approximately $3 / 4$ of fracture-related costs are attributable to hip fractures, and these are mostly covered by Medicare [1]. The rates of hip fracture rise exponentially between the 6th and 8th decades of life [6], and the rate doubles in patients with dementia [7]. While about $50 \%$ of patients with hip fracture may potentially return to their pre-fracture functional level, patients with dementia suffer worse post-fracture functional impairment $[8,9]$. Although limited, a few research studies reported the benefit of posthip fracture rehabilitation in dementia patients [7, 10, 11]. Yet, these patients are often left out from rehabilitation, because they are not recognized as good candidates [7]. Discharge coordination in association with rehabilitation and destination sites are reported barriers for a longer hospital LOS [11]; dementia adds to this process by increasing LOS and hospital charges [12-15].

Presence of comorbidities measured by the Charlson Comorbidity Index (CCI) has been associated with higher risk of hip fracture and higher post-fracture mortality $[5,16]$. While dementia, including Alzheimer's diseases, is part of the CCI calculator, it is not clear how the presence of dementia may affect hospital outcomes in older patients with hip fractures. A fracture is often the first sign of osteoporosis (OP) and is thus diagnosed clinically during post-hip fracture hospitalization [17]. Research describing LOS and acute care charges for hip fractures has mostly focused on these outcomes in trauma patients without a known pre-admission diagnosis of OP. Yet, an appropriate disease specific follow up plan may be missed if a diagnosis is not documented in chart [18]. Whether having a pre-fracture diagnosis of OP would have an effect on hospital outcomes in dementia patients has not been explored.

LOS and hospital charges for dementia patients are usually higher than those without dementia [12-14]. One US study has mentioned shorter LOS in patients with or without dementia after TAVR [19]. However, there is a gap in knowledge about LOS in patients with dementia who suffered a hip fracture. Furthermore, hip fracture patients with dementia have a higher risk of discharge to nursing homes (NHs) and worse health outcomes [16]. Previous research reported fracture-related health care costs that included hospital charges and follow-up care for up to 6 months after the hip fracture [20]. However, hospital charges during acute care for patients with a hip fracture with or without dementia, and with or without a pre-fracture diagnosis of OP, has not been discussed.

In this study, we aim to investigate whether having a diagnosis of OP, dementia, or both has an effect on the following hospital outcomes: i) LOS, ii) hospital charges, and iii) discharge destinations in Medicare beneficiaries who suffered a hip fracture in the USA. Specifically, we report the outcomes for four patient groups: i) having a diagnosis of dementia, ii) having a diagnosis of OP, ii) having a diagnosis of both dementia and OP, and iv) having no diagnosis of dementia or OP. In addition, we report prevalence of common comorbidities in the study population and their effects on hospital outcomes.

\section{Methods}

\section{Data source}

Claims data for a random sample of 100,000 Medicare beneficiaries (2012-2013) from the Centers for Medicare and Medicaid Services (CMS) were used as the data source for the current study. Medicare data provide beneficiary summary files, claims, and assessment data that are linked by a unique beneficiary identification number across different files. We used several files to obtain information on comorbidities, eligibility, and inpatient admissions. Information on inpatient claims regarding hospitalization due to hip fracture was obtained using the inpatient base claims version $j$ file. Comorbidities were determined using the Medicare Master Beneficiary Chronic Conditions file, which contains the first occurrence date of the chronic condition. If the first occurrence date of the chronic condition occurred prior to the hip fracture, we considered the comorbidity to be present. Medicare eligibility was determined using the Master Beneficiary Summary files for Parts A, B, and D.

\section{Study sample}

All Medicare beneficiaries with a hip fracture between 7/ $1 / 2012$ and 12/31/2013 were identified from CMS 
inpatient data. As part of a larger study evaluating postfracture function, only those with a long-term minimum data set (MDS) assessment after hospital discharge were included in the sample. Furthermore, we only included beneficiaries who were eligible for Medicare Part A/B/D for at least 180 days prior to the hip fracture. Lastly, we excluded from our sample all patients under 65 years old.

\section{Outcome variables}

Our primary outcomes variables were LOS and hospital charges for the hip fracture. LOS was the number of days spent in the hospital for hip fracture, including the admission and discharge dates. Hospital charges were provided as a total of all services included on the institutional claim for hip fracture (clm_tot_chrg_amt) (codes for hip fractures are listed in supplementary Table 1). Charges from physicians were not included. Our secondary outcome, discharge destination, was determined from the discharge status code (ptnt_dschrg_stud_cd) on the claim indicating the final disposition of the patient after discharge for the hip fracture event (supplementary Table 2). The 43 possible codes for discharge status were grouped into 6 categories: Home, Skilled Nursing Facility/Nursing Homes (SNF/NH), Inpatient Rehabilitation, Acute Care, Died/Hospice, and Other.

\section{Other variables}

We collected demographic information from the Master Beneficiary Summary Part A/B file, including sex, race, and age, which was expressed in years and calculated as of the end of the calendar year when the hip fracture occurred. The seven codes for race were categorized as either White or Other, since a majority of the patients in this study was White. The Medicare Master Beneficiary Chronic Conditions file was used to identify the presence of Alzheimer's disease (AD) or OP. Due to limitation of use of claims data, we used the term dementia (this includes dementia in general including AD) for the current manuscript. If the first occurrence date for dementia or OP was prior to the date of hip fracture, then we counted these patients in the dementia group or the OP group. Similarly, in this manner we determined other comorbidities such as congestive heart failure (CHF), chronic kidney disease (CKD), diabetes, hypertension, ischemic heart disease (IHD), and acute myocardial infarction (AMI).

\section{Data analysis plan}

Initially, a univariate test of equality for LOS among the four clinical groups-OP only, dementia only, both diagnoses, and neither diagnosis-was planned. The LOS was skewed, thus the nonparametric Kruskal-Wallis test was used. Possible associations between group and race, sex, and comorbidities were explored using Chi-square tests with three degrees of freedom (df). The null hypothesis that the median age at the time of fracture was the same for all four groups was tested by a Kruskall-Wallis test. Beneficiary characteristics significantly associated with the clinical group were used as covariates in a multiple linear regression. Surgical repair was also included in the model as it directly impacts LOS. Due to the asymmetric distribution of LOS, the log transformation of LOS was modeled. A full model was chosen to avoid underfitting and the accompanying bias. To satisfy model assumptions, a generalized gamma regression model was used to model the natural $\log$ of LOS across the groups and control for sex, race, age at fracture, and comorbidities. The distribution of the residuals was specified as gamma.

We followed a similar process for the analysis of hospital charges. The distribution was skewed, and thus a Kruskal-Wallis test of equality was used to compare median hospital charges for the four groups. Next, a generalized linear regression was used to examine the log transformation of total hospital charges across groups in the presence of covariates. Surgical repair was included in the model given its relationship to cost. Model assumptions were met by using a generalized gamma regression model for the natural log of hospital charges and specifying a gamma distribution for the residuals.

The distribution of discharge status in the four groups was compared using a Chi-square (row mean scores differ) test with $\mathrm{df}=3$. The data were stratified by clinical group.

A statistical significance level of .05 was used for all tests, and no adjustments were made for multiple tests. The analysis for this project was generated using SAS software, Version 9.4 of the SAS System for Windows (SAS Institute, Inc., Cary, NC).

This study was exempt by the Institutional Review Board (IRB) according to national regulations by the IRB of the University of North Texas Health Science Center. University of Kansas Medical Center had a data use agreement with Center for Medicare and Medicaid Services (CMS) and also had IRB approval for CMS data analysis.

\section{Results}

The initial sample consisted of 5331 Medicare beneficiaries aged $\geq 65$ years, admitted with a hip fracture between July 1, 2012, and December 31, 2013. A total of 2175 patients met all inclusion criteria and were included in our analysis (Fig. 1). Figure 1 is showing the flowchart of the study cohort pulled from CMS claims datasets of Medicare beneficiaries. Several analytical variables were created using real-world claims and coding to generate an accurate study cohort and report our study findings in detail. The supplementary tables include ICD-9-CM codes for fracture type and surgical 


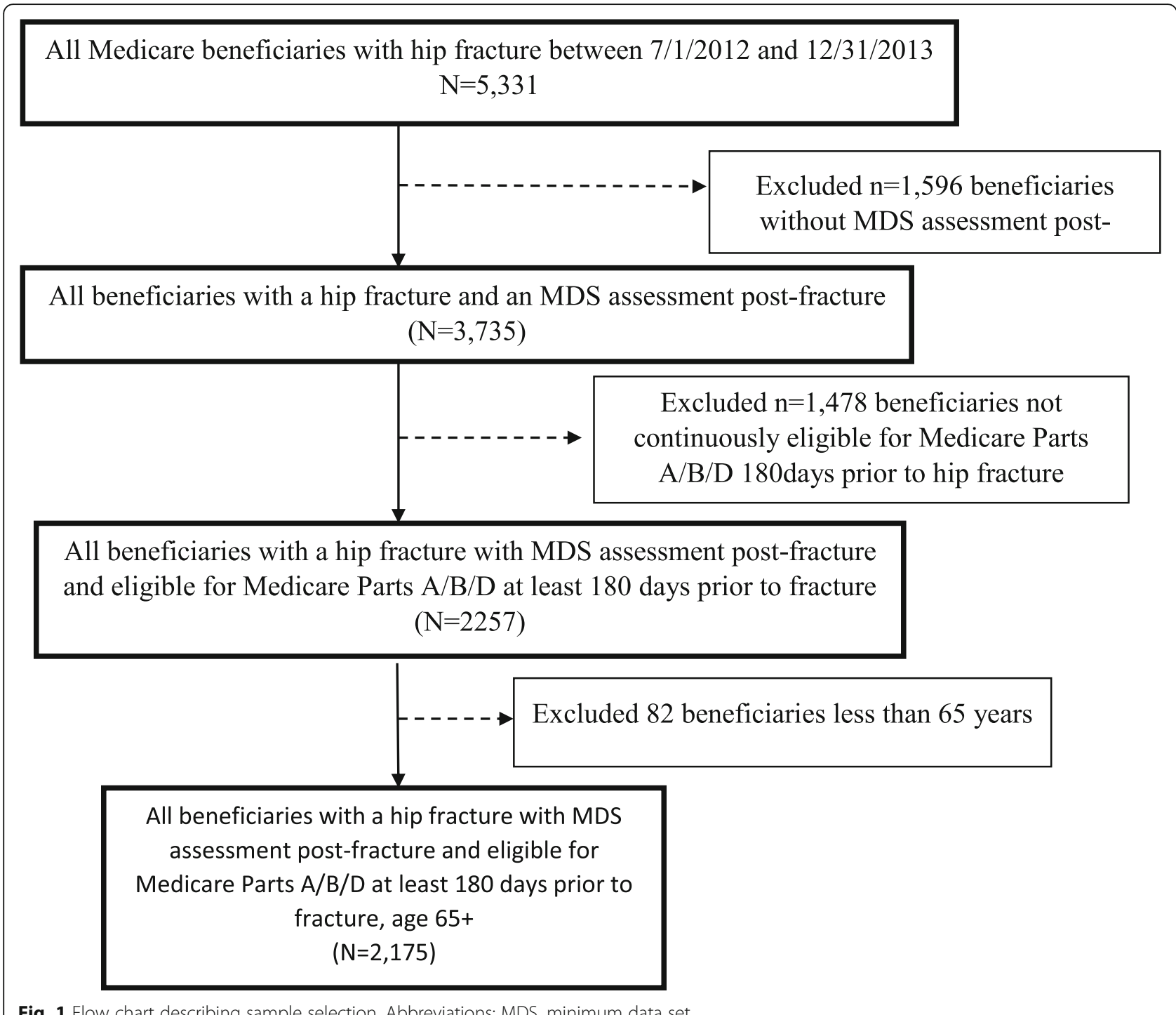

Fig. 1 Flow chart describing sample selection. Abbreviations: MDS, minimum data set

repair and categorization of important analytical variables used for this study analyses.

The results presented in Table 1 describe demographic and clinical characteristics, including type of hip fractures and chronic comorbidities, in the study population, which mostly consisted of women (77\%) and patients with a White race/ethnic background (92\%). The group with no OP and no dementia (reference group for our analysis) was the largest (40\%) in number and the youngest, with more than half of them (54\%) in the younger (65-84 years) age group (Table 1). The different fracture types that occurred in these patients were femoral neck (51\%), intertrochanteric (44\%), and subtrochanteric (5\%). Inter-trochanteric hip fracture was most common among the groups with OP alone or combined with dementia, whereas femoral neck was the most frequent site of fracture among those without any OP (dementia only and the reference group). Close to $90 \%(n=1976)$ of patients underwent surgical treatment for their hip fractures, but there was a tendency to fewer surgeries in the dementia groups (88\% versus 91-92\%). Hypertension was the most common comorbidity amongst all, followed by CHF, which was diagnosed most often among those with OP alone or in combination with dementia.

Race, sex, CHF, depression, hypertension, hyperlipidemia, IHD, and rheumatoid arthritis/osteoarthritis demonstrated statistically significant differences in at least one of the four clinical groups. AMI, CKD, and diabetes were not distributed differently across the groups (Table 1 ).

The average age at the time of the hip fracture was 84 years for all patients; the average age within each group was as follows: 85 years for the dementia group, 85 years for the OP group, 87 years for the dementia/OP group, and 83 years for the neither dementia/OP group. 
Table 1 Population characteristics for the four clinical groups

\begin{tabular}{|c|c|c|c|c|c|c|}
\hline \multirow[t]{2}{*}{ Characteristic } & \multirow{2}{*}{$\begin{array}{l}\text { All } \\
\text { N (\%) }\end{array}$} & \multicolumn{4}{|l|}{ Clinical groups } & \multirow[t]{2}{*}{$P *$} \\
\hline & & $\begin{array}{l}\text { Dementia Only } \\
\text { N (\%) }\end{array}$ & $\begin{array}{l}\text { OP Only } \\
\mathrm{N}(\%)\end{array}$ & $\begin{array}{l}\text { Both OP and dementia } \\
\mathrm{N}(\%)\end{array}$ & $\begin{array}{l}\text { Neither OP nor dementia } \\
\text { N (\%) }\end{array}$ & \\
\hline Sample size & $2175(100)$ & $279(13)$ & $774(36)$ & $247(11)$ & $875(40)$ & \\
\hline Sex, Female & $1679(77)$ & $176(63)$ & 708 (91) & $224(90)$ & $571(65)$ & $<.01$ \\
\hline Race, White & $2006(92)$ & $240(86)$ & $731(94)$ & $227(91)$ & $808(92)$ & $<.01$ \\
\hline \multicolumn{7}{|l|}{ Age } \\
\hline $65-84$ years & $1030(47)$ & $123(44)$ & $334(43)$ & $93(37)$ & $480(54)$ & $<.01$ \\
\hline $85+$ years & $1145(53)$ & $156(56)$ & $440(56)$ & $154(62)$ & 395 (45) & \\
\hline Median (IQR) & $85(79,90)$ & $86(80,90)$ & $86(80,90)$ & $87(83,91)$ & $83(77,89)$ & \\
\hline Fracture type & & & & & & $<.01$ \\
\hline Femoral Neck & $1114(51)$ & $161(57)$ & $362(46)$ & $113(45)$ & $478(54)$ & \\
\hline Intertrochanteric & $960(44)$ & 109 (39) & $372(48)$ & $126(51)$ & $353(40)$ & \\
\hline Subtrochanteric & $101(5)$ & $<10(3)$ & $40(5)$ & $<10(3)$ & $44(5)$ & \\
\hline Surgical repair of fracture & $1980(91)$ & $247(88)$ & $710(91)$ & $218(88)$ & $805(92)$ & .12 \\
\hline \multicolumn{7}{|l|}{ Comorbidities } \\
\hline Congestive heart failure & $1097(50)$ & $137(49)$ & $404(52)$ & $148(59)$ & $408(46)$ & $<.01$ \\
\hline Chronic kidney disease & 848 (39) & $110(39)$ & $291(37)$ & $113(45)$ & 334 (38) & .13 \\
\hline Diabetes & $931(43)$ & $120(43)$ & $308(39)$ & $105(42)$ & $398(45)$ & .14 \\
\hline Hypertension & $2021(93)$ & $262(93)$ & 729 (94) & $236(95)$ & $794(90)$ & .01 \\
\hline Acute myocardial infarction & $205(9)$ & $19(6)$ & $66(8)$ & $23(9)$ & $97(11)$ & .12 \\
\hline Ischemic Heart Disease & $1474(68)$ & $193(69)$ & $530(68)$ & $183(74)$ & $568(64)$ & .04 \\
\hline Hyperlipidemia & $1767(81)$ & $232(83)$ & $656(84)$ & $198(80)$ & $681(77)$ & $<.01$ \\
\hline Depression & $1154(53)$ & $190(68)$ & $391(50)$ & $180(72)$ & $393(44)$ & $<.01$ \\
\hline Arthritis $^{a}$ & $1612(74)$ & $193(69)$ & $625(80)$ & $214(86)$ & $580(66)$ & $<.01$ \\
\hline
\end{tabular}

Abbreviations: IQR interquartile range, $O P$ osteoporosi

${ }^{*} P$ values are for Chi-square tests examining the distribution across the four groups, except for age: Kruskal-Wallis was used

${ }^{\text {a }}$ Rheumatoid arthritis or osteoarthritis

Table 2 reports the distribution of LOS, discharge destination, and hospital charges by the four clinical groups. LOS and hospital charges were similar for all groups (Table 2). Median LOS was 6 days (IQR: $5-7$ ), and hospital discharge status was distributed similarly across each of the four groups (Cochran-Mantel-Haenszel $=$ 6.8210; $\mathrm{df}=3 ; P=0.0778$; row means differ). Median hospital charges were $\$ 45,100$ (IQR: $31,500-65,600$ ). Most beneficiaries were discharged to a nursing facility, including a SNF $(n=1777 ; 81.5 \%)$, while about $10.5 \%$

Table 2 Length of stay, hospital charge, and discharge destinations for the four clinical groups

\begin{tabular}{llllll}
\hline & \multicolumn{6}{l}{ Clinical Group } & & & \\
\cline { 2 - 5 } & All & Dementia only & OP only & Both OP and Dementia & Neither OP nor Dementia \\
\hline \multirow{2}{*}{ Length of stay (days) } & $6(5-7)$ & $6(5-7)$ & $6(5-7)$ & $6(5-7)$ & Median (IQR) \\
Hospital charges (\$1000) & $45(3166)$ & $43(30-68)$ & $46(32-66)$ & $44(30-64)$ & $6(5-8)$ \\
Hospital discharge status* & $\mathrm{N}(\%)$ & $\mathrm{N}(\%)$ & $\mathrm{N}(\%)$ & $\mathrm{N}(\%)$ & $46(32-66)$ \\
Home & $67(3 \%)$ & $12(4 \%)$ & $20(2 \%)$ & $11(4 \%)$ & $\mathrm{N}(\%)$ \\
Inpatient Rehab & $228(10.5 \%)$ & $18(6 \%)$ & $91(11 \%)$ & $20(8 \%)$ & $24(2 \%)$ \\
SNF/NH & $1772(81.5)$ & $229(82 \%)$ & $631(81 \%)$ & $201(81 \%)$ & $99(11 \%)$ \\
Acute care & $73(3 \%)$ & $12(4 \%)$ & $26(3 \%)$ & $<10(1 \%)$ & $311(81 \%)$ \\
Died/Hospice & $35(2 \%)$ & $<10(2 \%)$ & $<10(0 \%)$ & $11(4 \%)$ & $10(1 \%)$ \\
\hline
\end{tabular}

Abbreviations: IQR interquartile range, $N H$ nursing home, $O P$ osteoporosis, SNF specialized nursing facility

${ }^{*}$ Chi-square test $\mathrm{df}=3$ (row mean scores differ), statistic $=6.8210, P=0.0778$ 
proceeded to inpatient rehabilitation (Table 2). Although not statistically significant, lower percentages of patients from the dementia groups (dementia only, $6 \%$ vs. group with dementia and OP, $8 \%$ ) went to inpatient rehabilitation.

Table 3 reports the results from the multiple regression analysis showing association of LOS with the four clinical groups. No statistically significant difference was observed among the groups (Kruskal-Wallis, $\mathrm{H}=2.79$; $\mathrm{df}=3 ; P=$ 0.4243). Having a diagnosis of dementia was associated with a $5 \%$ shorter LOS. Similarly, White patients had a $7 \%$ shorter LOS, and those with CHF (+ 7\%) and IHD (+ 4\%) had longer LOS. Unsurprisingly, surgical patients were hospitalized 63\% longer than non-surgical patients.

Table 4 reports results the from the multiple regression analysis showing associations between total hospital charges with the four clinical groups. No statistically significant difference was observed among the four groups (Kruskal-Wallis $\mathrm{H}=1.9468 ; \mathrm{df}=3 ; P=0.5835$ ). Given that many patient characteristics were associated with group inclusion, we were curious to see how hospital total charges compared across the four groups when adjusting for covariates. All the covariates significantly associated with patient group were included in a regression model. The full model suggests that there is no difference in hospital charges for the four groups after adjusting for sex, race, surgery, and comorbidities. However, after adjusting

Table 3 Results of the multiple regression analysis for hospital length of stay

\begin{tabular}{|c|c|c|}
\hline Parameter & $\begin{array}{l}\text { Exponentiated Coefficient (95\% } \\
\text { Confidence Interval) }\end{array}$ & $P$ \\
\hline Intercept & $3.99(3.25,4.91)$ & $<.01$ \\
\hline Dementia only & $.95(.90,1.0)$ & .04 \\
\hline OP only & $1.00(.97,1.04)$ & .85 \\
\hline $\begin{array}{l}\text { Both OP and } \\
\text { Dementia }\end{array}$ & $.96(.91,1.0)$ & .12 \\
\hline $\begin{array}{l}\text { Neither OP nor } \\
\text { Dementia }\end{array}$ & reference & \\
\hline Female & $.98(.94,1.02)$ & .34 \\
\hline Race, White & $.93(.88, .99)$ & .02 \\
\hline Age at fracture & $1.00(1.00,1.00)$ & .24 \\
\hline $\begin{array}{l}\text { Congestive heart } \\
\text { failure }\end{array}$ & $1.07(1.04,1.11)$ & $<.01$ \\
\hline Depression & $1.00(.97,1.03)$ & .89 \\
\hline Hypertension & $1.02(.96,1.09)$ & .56 \\
\hline Hyperlipidemia & $.97(.93,1.01)$ & .20 \\
\hline $\begin{array}{l}\text { Ischemic heart } \\
\text { disease }\end{array}$ & $1.04(1.00,1.08)$ & .03 \\
\hline Arthritis $^{a}$ & $1.01(.97,1.05)$ & .63 \\
\hline $\begin{array}{l}\text { Surgical repair of } \\
\text { fracture }\end{array}$ & $1.63(1.53,1.74)$ & $<.01$ \\
\hline
\end{tabular}

Abbreviations: OP osteoporosis

${ }^{\mathrm{a}}$ Rheumatoid arthritis or osteoarthritis
Table 4 Results of the multiple regression analysis for total hospital charges

\begin{tabular}{|c|c|c|}
\hline & $\begin{array}{l}\text { Exponentiated Estimate (95\% } \\
\text { Confidence Interval) }\end{array}$ & $P$-value \\
\hline Intercept & $23,327.8(16,831.4,32,331.6)$ & $<.01$ \\
\hline Dementia only & $.95(.87,1.03)$ & .18 \\
\hline OP only & $1.00(.95,1.07)$ & .90 \\
\hline $\begin{array}{l}\text { Both OP and } \\
\text { Dementia }\end{array}$ & $1.00(.92,1.10)$ & .91 \\
\hline $\begin{array}{l}\text { Neither OP nor } \\
\text { Dementia }\end{array}$ & reference & \\
\hline Female & $.95(.89,1.01)$ & .08 \\
\hline Race, White & $.84(.77, .92)$ & $<.01$ \\
\hline Age at fracture & $1.00(.99,1.00)$ & .01 \\
\hline $\begin{array}{l}\text { Congestive heart } \\
\text { failure }\end{array}$ & $1.08(1.02,1.14)$ & .01 \\
\hline Depression & $.98(.93,1.04)$ & .54 \\
\hline Hypertension & $1.00(.90,1.11)$ & .96 \\
\hline Hyperlipidemia & $.99(.92,1.05)$ & .67 \\
\hline $\begin{array}{l}\text { Ischemic heart } \\
\text { disease }\end{array}$ & $1.07(1.01,1.14)$ & .03 \\
\hline Arthritis $^{a}$ & $1.04(.98,1.10)$ & .23 \\
\hline $\begin{array}{l}\text { Surgical repair of } \\
\text { fracture }\end{array}$ & $3.19(2.88,3.54)$ & $<.01$ \\
\hline
\end{tabular}

Abbreviations: $O P$ osteoporosis

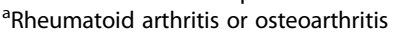

for group, race, surgery, and comorbidities, hospital charges were $6 \%$ lower for women compared to men, and $16 \%$ lower for Whites vs. non-Whites. Factors associated with higher hospital charges, after adjusting for group, race, surgery, and comorbidities, were CHF (7\% increase), IHD (7\% increase), and surgical repair (320\% increase).

Although there was no statistically significant difference in discharge destination between the groups, most patients (4/5) went to a SNF or $\mathrm{NH}$ after discharge. Fewer percentages from the groups with dementia went to inpatient rehabilitation (Table 2).

\section{Discussion}

We report LOS, hospital charges, discharge destination, and chronic comorbidities in Medicare beneficiaries of the USA in four clinical groups based on their diagnosis of OP and dementia prior to hip fracture. Compared to the reference group, patients with dementia only (without OP) had a $5 \%$ shorter LOS $(P=0.04)$ when hospitalized for hip fracture. No significant differences were seen in hospital charges between the groups. Patients with CHF and IHD had longer LOS and higher hospital charges than those without CHF and IHD, regardless of their diagnosis of dementia or OP, and being a woman and White race were associated with lower hospital charges. There was a tendency for dementia patients to 
undergo surgery and be discharged to rehabilitation less frequently than the other groups; however, the trend in discharge status was not statistically significant.

Our findings are contrary to most previous reports about LOS in dementia patients. Studies have reported a longer LOS for patients with dementia in the past [12, $13,21]$, which is usually attributed to associated health complications leading to worse health status, including impaired orientation, functional abilities, and risk of fall $[13,15]$. Unlike our study, past studies have used data from patients with multiple comorbidities admitted to hospital for acute illnesses not related to hip fracture or OP. Chronic comorbidities were identified to be most likely contributor to increased LOS in patients with dementia worldwide [13]. Patients with CHF and IHD had higher LOS in our study than those without CHF and IHD. Although not statistically significant, prevalence of CHF, IHD, and depression in our study were slightly higher in the dementia group who also suffered from OP. One potential cause of the greater LOS is surgical intervention. The total percentage of patients undergoing surgical intervention in our study was similar to what was reported in Medicare beneficiaries with hip fracture [5]. However, the percentage of patients in the surgical intervention in our study was slightly lower in dementia patients regardless of their OP status. Associations of chronic comorbidities with longer LOS may indicate that LOS is not just an economic parameter but linked to management of medically complex patients.

Coordination of discharge to a facility often takes a longer LOS [22]. There was not much of a difference in percentages of patients between the four clinical groups who were discharged to nursing facilities, including SNFs and NHs. Discharge to home in our study, although low, was higher in dementia related groups (4\% in those with dementia alone or with OP vs. $2 \%$ in those with OP alone or the reference group). Compared to the dementia-related groups (6-8\%), larger percentages of patients (11\%) in the OP alone or reference group were discharged to inpatient rehabilitation. These small differences may not be enough to justify a shorter LOS in the patients with dementia in our study. More patients in the OP-related group proceeded to inpatient rehabilitation. No patient in the OP alone group was included in the hospice/mortality group, whereas $2-4 \%$ of the dementia-related groups were under this category. A similar percentage of patients in the dementia-related group in the discharge to home or hospice/mortality categories may indicate the frailer physical status of the dementia group. Higher prevalence of frailty is known to be more common among dementia patients with hip fractures [23]. Even without matching percentages, a previous study reported a similar pattern of distribution to discharge destinations for older patients hospitalized for hip fracture with or without some type of dementia [24]. Recent research showed functional improvement in patients with dementia who were sent home with outpatient rehabilitation therapy after the hip fracture event, more so when they had comprehensive geriatric care during rehabiliation [25]. We are limited in knowledge about the rehabilitation status among homebound patients. However, a higher percentage of patients being discharged to SNFs indicates that most of our patients were, physically and cognitively, qualified to participate in physical activity for rehabilitation. Although patients with dementia had a significantly shorter LOS in our study, the average LOS we report is similar to that determined in another study reporting LOS for hip fracture regardless of dementia status $[8,24]$. While we are limited in our reporting about patients' physical and functional abilities, a future study is recommended to explore this aspect of dementia patients with hip fracture, which may affect their health outcomes. One new information our results adds to the literature is that a prior diagnosis of OP did not make a difference in LOS which often linked to patients' management plan indicating complexity of medical conditions [13].

We did not report significant differences in hospital charges between the four clinical groups. However, women and Whites were more likely to have lower hospital charges that men and non-Whites. One study attributed higher hospital charges for inpatients with dementia due to their comorbidities complicating acute illness and a need for additional in-hospital procedures compared to the hospitalized non-dementia counterparts [12]. Having CHF or IHD posed risk to those having higher charges in our study. As mentioned in previous studies [13], a longer LOS for these patients with CHF and IHD may have contributed to higher hospital charges.

The distribution pattern in types of hip fracture in our study was similar to what was reported previously in older adults, where femoral neck fracture was the most common type (51\%), followed by inter-trochanteric fracture (44\%) [8]. There were significant differences in fracture types between the four clinical groups. Higher percentages of patients in OP-related groups (OP alone, $48 \%$; OP with dementia, $51 \%$ ) suffered from intertrochanteric fractures than in the dementia alone (39\%) or reference group (40\%). The opposite was noted for femoral neck fractures in our population, with lower percentages in the OP-related groups (OP alone, 46\%; OP with dementia, 45\%) than in those with dementia alone (57\%) and in the reference group (54\%). These distributions are consistent with previous study reports that attributed higher incidence of trochanteric fracture in osteoporotic patients due to severe bone loss in this hip region [6]. The mean age of hip fracture in our study is 
consistent with previous studies that did not clearly report distribution by dementia status $[6,8]$. Kim et al. reported the highest incidence of hip fracture in the mid80 s, which ranged between 84 and 88 years of age [6]. Our population showed similar age distribution without any significant differences between the four clinical groups. Although not sharing the source of study patients, our population seems to be similar to those of previous studies in terms of the pattern of osteoporotic fractures and age at the time of the fracture event. However, we add new information as we report these patterns in osteoporotic patients with or without dementia.

\section{Limitations}

There are several limitations with our study. Caution need to be applied when interpreting our results as we report data from the United States which may be different than what is reported in similar developed countries in other continents. However, hip fracture in older adults is a universal health problem; and thus our results may be informative when described with a focus on patients with dementia and other chronic diseases. While we were limited to patients who had an MDS assessment post hip-fracture, we were unable to determine if the admission to the long-term care facilities was related directly to the hip fracture: while over 50\% of MDS assessments were performed within a week of discharge, many people were first assessed months later. We do not know if this is due to late reporting or delayed admission. Furthermore, the MDS data were sparsely populated, and we were not able to analyze the MDS data for all the patients who had a hip fracture. We thus cannot rule out other baseline characteristics that may have been associated with outcomes. In addition, we did not determine if the person was living in a long-term care facility at the time of the fracture. Future studies need to consider the facility where the older patients are from to fully understand the extent of the setting's role in treatment decision making. However, use of Medicare data is a strength for our study. Medicare files are one of the robust claims dataset for older patients in the USA and a source for many health services research as they rely on real world evidence to help improve health care delivery system. One common limitation of all types of administrative/claims data is that they rely on coding and thus the diagnosis is ascertained from those coding in the dataset.

\section{Conclusion}

Our study reports valuable information about hospital outcomes among older Medicare beneficiaries in the USA with dementia and/or OP with hip fractures. To our knowledge, this is the first study reporting LOS in older patients with dementia who suffered a hip fracture.
Unlike previous studies on hospital outcomes in dementia patients, we report a $5 \%$ shorter LOS in these patients compared to those without any known diagnosis of dementia or OP. A lack of specific information on frailty, level of dementia, and life expectancy post-hip fracture in this particular group limits us from concluding on the reason for a shorter LOS in the dementia group. Regardless of the geographic source of data from the USA, our study brings a new perspective of hospital LOS since previous studies did not look at LOS in dementia in the context of hip fracture. Common comorbidities known for causing a higher LOS (in previous studies) have shown same pattern of LOS as in our study, regardless of clinical grouping. We recommend future studies to confirm our findings and compare similar data from other developed countries.

\section{Supplementary Information}

The online version contains supplementary material available at https://doi. org/10.1186/s12877-020-01924-x

Additional file 1: Supplementary Table 1. ICD-9-CM codes for fracture type and surgical repair.

Additional file 2: Supplementary Table 2. Categorization of variables.

\section{Abbreviations \\ LOS: Length of Stay; OP: Osteoporosis; CMS: Centers for Medicare and Medicaid Services; MDS: Minimum dataset; SNF: Skilled Nursing Facility; $\mathrm{NH}$ : Nursing homes; CHF: Congestive heart failure; IHD: Ischemic heart disease; AMl: Acute myocardial infarction; CKD: Chronic kidney disease; CCl: Charlson Comorbidity Index}

\section{Acknowledgements}

The authors would like to thank Patricia Fonseca for editorial assistance.

\section{Authors' contributions}

RR: Contributed in study conception, study design, data acquisition, interpretation of data, preparation and reviewing the manuscript. RZ and ARKM: Contributed to study design, interpretation of data, preparing and reviewing the manuscript. SLH: Contributed in study design, data acquisition, data analysis, interpreting results, preparation and reviewing the manuscript. MAP: Contributed in study design, data analysis, interpretation of results, and reviewing manuscript. NR: Contributed in study conception, study design, intrepreation of data, preparation and reviewing of the manuscript. Each author has approved the submitted version of the manuscript and have agreed to be personally accountable for the author's own contributions and to ensure that questions related to the accuracy or integrity of any part of the work, even ones in which authors was not personally involved, are appropriately investigated, resolved and the resolution documented in the literature.

Funding

Not Applicable.

\section{Availability of data and materials}

The data that support the findings of this study are available from the Center for Medicare and Medicaid Services but restrictions apply to the availability of these data, which were used under license for the current study, and so are not publicly available. Data are however available from the authors upon reasonable request and with permission of the Center for Medicare and Medicaid Services. 


\section{Ethics approval and consent to participate}

The study was exempt according to national regulations by the Institutional Review Board of the University of North Texas Health Science Center. This study was exempt by the Institutional Review Board (IRB) according to national regulations by the IRB of the University of North Texas Health Science Center. University of Kansas Medical Center had a data use agreement with the Center for Medicare and Medicaid Services (CMS) and also had IRB approval for the CMS data analysis

\section{Consent for publication}

Not Applicable.

\section{Competing interests}

The authors declare that they have no competing interests.

\section{Author details}

'Department of Pharmacotherapy "University of North Texas Health Science Center, College of Pharmacy, Fort Worth, TX, USA. ${ }^{2}$ Department of Health Behavior and Health Systems, University of North Texas Health Science Center, School of Public Health, Fort Worth, TX, USA. ${ }^{3}$ Department of Biostatistics and Data Science, University of Kansas Medical Center, School of Medicine, Kansas City, Kansas, USA. ${ }^{4}$ Department of Family and Community Medicine, The University of Texas Health Science Center at Houston, McGovern Medical School, 6341 Fannin Street, \#JJL 324C, Houston, TX 77030, USA. ${ }^{5}$ Division of Geriatric and Palliative Medicine, Department of Internal Medicine, The University of Texas Health Science Center at Houston, McGovern Medical School, TX, Houston, USA.

Received: 12 August 2020 Accepted: 22 November 2020 Published online: 03 December 2020

\section{References}

1. Lewiecki EM, Wright NC, Curtis JR, Siris E, Ggel RF, Saag KG, et al. Hip fracture trends in the United States, 2002 to 2015. Osteoporosis Int. 2018; 29(3):717-22.

2. Weycker D, Li X, Barron R, Bornheimer R, Chandler D. Hospitalizations for osteoporosis-related fractures: economic costs and clinical outcomes. Bone Rep. 2016:5:186-91.

3. Braithwaite RS, Col NF, Wong JB. Estimating hip fracture morbidity, mortality and costs. J Am Geriatr Soc. 2003;51(3):364-70.

4. Centers for Disease Control and Prevention. Hip Fractures Among Older Adults. Centers for Disease Control and Prevention. 2016. https://www.cdc. gov/homeandrecreationalsafety/falls/adulthipfx.html. Accessed 6 July 2020

5. Neuman MD, Silber JH, Magaziner JS, Passarella MA, Mehta S, Werner RM. Survival and functional outcomes after hip fracture among nursing home residents. JAMA Intern Med. 2014;174(8):1273-80.

6. Kim SH, Meehan JP, Blumfeld T, Szabo RM. Hip fractures in the United States: 2008 nationwide emergency department sample. Arth Care Res. 2012;64(5):751-7.

7. Rolland Y, Pillard F, Lauwers-Cances V, et al. Rehabilitation outcome of elderly patients with hip fracture and cognitive impairment. Disab Rehabil. 2004;26(7):425-31.

8. Marcantonio ER, Flacker JM, Michaels M, Resnick NM. Delirium is independently associated with poor functional recovery after hip fracture. J Am Geriatr Soc. 2000;48(6):618-24.

9. Seitz DP, Gill SS, Austin PC, Bell CM, Anderson GM, Gruneir A, et al. Rehabilitation of older adults with dementia after hip fracture. J Am Geriatr Soc. 2016:64(1):47-54.

10. Giusti A, Barone A, Pioli G. Rehabilitation after hip fracture in patients with dementia. J Am Geriatr Soc. 2007;55(8):1309-10.

11. Killington M, Davies W, Crotty M, Rhiannon C, Pratt N, Mills K, McInnes A, Kurrle $\mathrm{S}$, et al. People living in nursing care facilities who are ambulant and fracture their hips: description of usual care and an alternative rehabilitatoi pathway. BMC Geriatrics. 2020;20:128.

12. Beydoun MA, Gamaldo AA, Beydoun HA, Shaked D, Zonderman AB, Shaker ME. Trends, predictors, and outcomes of healthcare resources used in patients hospitalized with Alzheimer's disease with at least one procedure: the Nationwide inpatient sample. J Alzheimers Dis. 2017;57(3):813-24.

13. Connolly S, O'Shea $\mathrm{E}$. The impact of dementia on length of stay in acute hospitals in Ireland. Dementia (London). 2015;14(5):650-8.
14. Wang HK, Hung CM, Lin SH, Tai YC, Lu K, Liliang PC, et al. Increased risk of hip fractures in patients with dementia: a nationwide population-based study. BMC Neurol. 2014;14:175.

15. Motzek T, Junge M, Marquardt G. Impact of dementia on length of stay and costs in acute care hospitals. J Gerontol Geriatr. 2017;50(1):59-66.

16. Guzon-Illescas O, Perez Fernandez E, Crespi Villarias N, Quiros Donae FJ, Pena M, Alonso-Blas C, Garcia-Vadillo A, et al. Mortality after osteoporotic hip fracture: incidence, trends, and associated factors. J Orthop Surg Res. 2019;14(1):203.

17. Miller PD. Underdiagnoses and undertreatment of osteoporosis: the battle to be won. J Clin Endocrinol Metab. 2016;101(2):852-9.

18. Simonelli C, Chen Y-T, Morancey J, Lewis AF, Abott TA III. Evaluation and management of osteoporosis following hospitalizatin for low-impact fracture. J Gen Intern Med. 2003;18:17-22.

19. Kwak MJ, Rasu R, Morgan RO, Lee J, Rianon NJ, Holmes HM, Dhoble A, Kim $\mathrm{DH}$. The association of economic outcomes and geriatric syndromes among older adults with Transcatheter aortic valve replacement (TAVR). JHEOR. 2020;7(2):175-81.

20. Kapinos KA, Fischer SH, Mulcahy A, Hayden O, Barron R. Medical costs for osteoporosis-related fractures in high-risk Medicare beneficiaries. J Am Geriatr Soc. 2018;66(12):2298-304.

21. Briggs R, Dyer A, Nabeel S, Collins R, Doherty J, Coughlan T, et al. Dementia in the acute hospital: the prevalence and clinical outcomes of acutely unwell patients with dementia. QJM. 2017;110(1):33-7.

22. Zhao EJ, Yeluru A, Manjunath L, Zhong LR, Hsu H-T, Lee C, et al. A long wait: barriers to discharge for long length of stay patients. Postgrad Med J. 2018;94(1116):546-50.

23. Menzies IB, Mendelson D, Kates S, Frieman SM. Prevention and clinical management of hip fractures in patients with dementia. Geriatr Orthop Surg Rehabil. 2010;1(2):63-72.

24. Nguyen-Oghalai TU, Kuo YF, Zhang DD, Graham JE, Goodwin JS, Ottenbacher KJ. Discharge setting for patients with hip fracture: trends from 2001 to 2005. J Am Geriatr Soc. 2008;56(6):1063-8.

25. Prestmo A, Saltvedt I, Helbostad JL, Taraldsen K, Thingstad P, Lydersen S, Sletvold $\mathrm{O}$. Who benefits from orthogeriatric treatment? Results from the Trondheim hip-fracture trial. BMC Geriatrics. 2016;16:49.

\section{Publisher's Note}

Springer Nature remains neutral with regard to jurisdictional claims in published maps and institutional affiliations.
Ready to submit your research? Choose BMC and benefit from:

- fast, convenient online submission

- thorough peer review by experienced researchers in your field

- rapid publication on acceptance

- support for research data, including large and complex data types

- gold Open Access which fosters wider collaboration and increased citations

- maximum visibility for your research: over $100 \mathrm{M}$ website views per year

At BMC, research is always in progress.

Learn more biomedcentral.com/submissions 